Supplement of Clim. Past, 12, 575-593, 2016

http://www.clim-past.net/12/575/2016/

doi:10.5194/cp-12-575-2016-supplement

(C) Author(s) 2016. CC Attribution 3.0 License.

(c) (i)

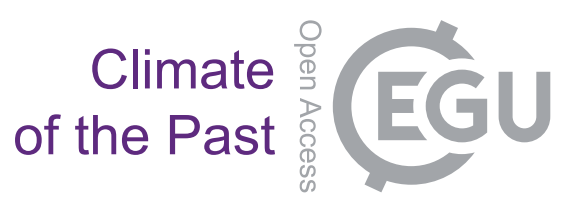

Supplement of

\title{
Impacts of climate and humans on the vegetation in northwestern Turkey: palynological insights from Lake Iznik since the Last Glacial
}

Andrea Miebach et al.

Correspondence to: Andrea Miebach (a.miebach@uni-bonn.de)

The copyright of individual parts of the supplement might differ from the CC-BY 3.0 licence. 
Supplementary Material: Complete pollen diagram inferred from Lake Iznik sediments with terrestrial plants in percentages, aquatic plants in concentrations, total pollen concentrations, and total pollen influxes (pollen accumulations). Uncalibrated radiocarbon dates and tephra layers according to Ülgen et al. (2012) and Roeser (2014). Radiocarbon dates marked by a star are from bulk organic and are therefore subjected to reservoir effects.
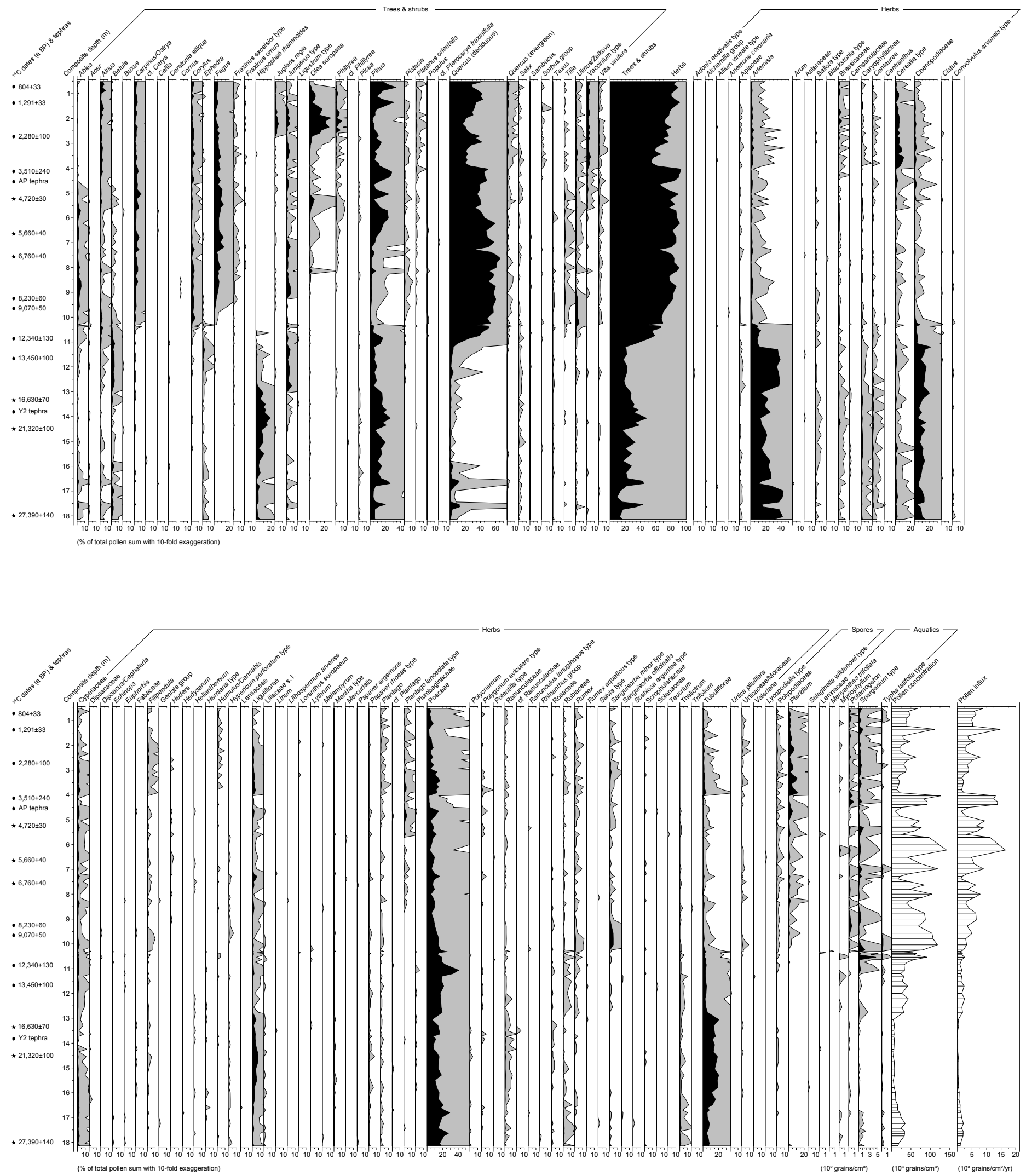